\title{
Complete oxidation of acetaldehyde over a composite photocatalyst of graphitic carbon nitride and tungsten(VI) oxide under visible-light irradiation
}

Zhengyuan Jin ${ }^{\mathrm{a}}$, Naoya Murakami ${ }^{\mathrm{a}}$, Toshiki Tsubota ${ }^{\mathrm{a}}$, Teruhisa Ohno ${ }^{\mathrm{a}, \mathrm{b}, \mathrm{c},{ }^{*}}$

${ }^{a}$ Department of Applied Chemistry, Faculty of Engineering, Kyushu Institute of Technology, 1-1 Sensuicho, Tobata, Kitakyushu 804-8550, Japan

b JST, PRESTO, 4-1-8 Honcho Kawaguchi, Saitama 332-0012, Japan

c JST, ACT-C, 4-1-8 Honcho Kawaguchi, Saitama 332-0012, Japan

${ }^{*}$ Corresponding author

Tel and fax: 81-93-884-3318

E-mail: tohno@che.kyutech.ac.jp

\begin{abstract}
Graphitic carbon nitride $\left(\mathrm{g}-\mathrm{C}_{3} \mathrm{~N}_{4}\right)$ was prepared by heating melamine and then its specific surface area was enlarged by hydrothermal treatment in aqueous sodium hydroxide solution. The $\mathrm{g}-\mathrm{C}_{3} \mathrm{~N}_{4}$ samples were blended with tungsten(VI) oxide $\left(\mathrm{WO}_{3}\right)$ using a planetary mill in order to improve photocatalytic activity. The composite photocatalyst with optimized amounts of these contents showed higher photocatalytic activity for decomposition of acetaldehyde under visible-light irradiation than did original samples. From the results, we concluded that the composite photocatalyst utilizes both high oxidation ability of $\mathrm{WO}_{3}$ and high reduction ability of $\mathrm{g}-\mathrm{C}_{3} \mathrm{~N}_{4}$ by Z-scheme charge transfer.
\end{abstract}

Keyword: g- $\mathrm{C}_{3} \mathrm{~N}_{4}$; $\mathrm{WO}_{3}$; photocatalysis; planetary mill; Z-scheme. 


\section{Introduction}

Titanium(IV) oxide $\left(\mathrm{TiO}_{2}\right)$ is the most widely used photocatalyst because of its excellent oxidation ability, availability and stability [1]. However, there are two major problems with a conventional $\mathrm{TiO}_{2}$ photocatalyst: it is inactive under visible-light irradiation and it has low quantum efficiency due to a high recombination rate of photogenerated electron-hole pairs. There have been numerous studies on $\mathrm{TiO}_{2}$ with impurity doping $[2,3]$, co-catalyst loading [4] and shape control $[5,6]$ for improvement of visible-light response and reaction efficiency of electrons and holes, though these methods still have limitations for improvement of solar energy conversion efficiency.

It is rather challenging to design a semiconductor photocatalyst fulfilling the multiple requirements. Actually, a single semiconductor with large visible-light absorption has difficulty in exhibiting both high reduction and oxidation abilities due to its narrow bandgap structure. Therefore, a composite photocatalyst consisting of different kinds of semiconductors has been studied in recent years. Some studies showed that an appropriate composition of two kinds of photocatalyst enhanced photocatalytic activity as a result of charge separation between two semiconductors [7-12]. This mechanism employs interparticle electron transfer to one semiconductor with a more positive conduction band (CB) potential and hole transfer to the other semiconductor with a more negative valence band (VB) potential. Thus, this kind of composite photocatalyst cannot utilize both high reduction and oxidation abilities. In contrast, another reaction mechanism for a composite photocatalyst, namely, Z-scheme reaction mechanism, has been suggested in several reports [13-17]. This mechanism enables a composite photocatalyst to utilize both reduction ability for one semiconductor with more negative $\mathrm{CB}$ potential and oxidation ability for another semiconductor with more positive VB potential as a result of two-step excitation. Thus, a Z-scheme composite photocatalyst is one means for utilizing both high oxidation and reduction abilities under visible-light irradiation if appropriate semiconductors are used.

In our previous study, a composite of graphitic carbon nitride $\left(\mathrm{g}-\mathrm{C}_{3} \mathrm{~N}_{4}\right)$, which is an organic semiconductor with visible-light absorption, high reduction ability and high chemical stability [18], with sulfur-doped $\mathrm{TiO}_{2}$ was made [19]. In that study, the composite sample prepared by a planetary mill showed high photocatalytic activity for acetaldehyde decomposition under visible-light irradiation as a result of 
Z-scheme charge transfer. Thus, the sample showed both high oxidation ability of sulfur-doped $\mathrm{TiO}_{2}$ and high reduction ability of $\mathrm{g}-\mathrm{C}_{3} \mathrm{~N}_{4}$. However, it was concluded that photoabsorption of sulfur-doped $\mathrm{TiO}_{2}$ and small specific surface area of $\mathrm{g}-\mathrm{C}_{3} \mathrm{~N}_{4}$ are bottlenecks for further enhancement of photocatalytic activity.

Tungsten(VI) oxide $\left(\mathrm{WO}_{3}\right)$ may be ideal for a combination pair with $\mathrm{g}-\mathrm{C}_{3} \mathrm{~N}_{4}$ in the $\mathrm{Z}$-scheme reaction because it is well known as an oxidation part photocatalyst for Z-scheme photocatalytic water splitting [14]. Moreover, it has larger visible-light absorption than that of sulfur-doped $\mathrm{TiO}_{2}$. $\mathrm{WO}_{3}$ without a co-catalyst is thought to be inappropriate for organic decomposition due to inferior reductive potential of the $\mathrm{CB}$ for one-electron reduction of oxygen $\left(\mathrm{O}_{2}\right)$. Therefore, a co-catalyst metal for multi-electron reduction of $\mathrm{O}_{2}[20$, 21] or a reduction part semiconductor with sufficient negative $\mathrm{CB}$ potential for one-electron reduction of $\mathrm{O}_{2}$ in the Z-scheme reaction [15-17] is necessary for complete oxidation of organic compounds over $\mathrm{WO}_{3}$. Although there have been some reports of composite photocatalysts with g- $\mathrm{C}_{3} \mathrm{~N}_{4}$ including $g-\mathrm{C}_{3} \mathrm{~N}_{4} / \mathrm{WO}_{3}[7$, 9-11, 22-24], a charge separation mechanism was employed in those photocatalysts, and explanation of the mechanism was not sufficient. Complete oxidation of organic compounds into carbon dioxide $\left(\mathrm{CO}_{2}\right)$ was not discussed in photocatalytic evaluation.

In this study, a composite of $\mathrm{g}-\mathrm{C}_{3} \mathrm{~N}_{4}$, which was prepared by heat treatment of melamine [25], and $\mathrm{WO}_{3}$ was prepared by using a planetary mill and its photocatalytic activity for acetaldehyde decomposition was discussed from the viewpoint of complete oxidation into $\mathrm{CO}_{2}$. Moreover, g- $\mathrm{C}_{3} \mathrm{~N}_{4}$ with a large specific surface area, which was obtained by hydrothermal treatment of original g- $\mathrm{C}_{3} \mathrm{~N}_{4}$ in sodium hydroxide $(\mathrm{NaOH})$ solution [26], was used for the composite photocatalyst in order to improve photocatalytic activity.

\section{Experimental}

\subsection{Materials}

All chemicals were reagent grade and used without further purification. g- $\mathrm{C}_{3} \mathrm{~N}_{4}$ powder was synthesized by heating $30 \mathrm{~g}$ of melamine at $823 \mathrm{~K}$ at a heating rate of $9 \mathrm{~K} \cdot \mathrm{min}^{-1}$, followed by heating for 4 hours at that temperature. The product was collected and ground into powder. $\mathrm{WO}_{3}$ powders were commercial samples (Kojundo Chemical Laboratory Co.).

\subsection{Hydrothermal treatment of $\mathrm{g}-\mathrm{C}_{3} \mathrm{~N}_{4}$ in $\mathrm{NaOH}$ solution}


The specific surface area of $g-\mathrm{C}_{3} \mathrm{~N}_{4}$ was enlarged by hydrothermal method [26]. One gram of as-prepared g- $\mathrm{C}_{3} \mathrm{~N}_{4}$ powder was added to $50 \mathrm{~mL}$ of $0.1 \mathrm{M}$ aqueous $\mathrm{NaOH}$ solution. The suspension was ultrasonicated for $10 \mathrm{~min}$ to completely disperse the $\mathrm{g}-\mathrm{C}_{3} \mathrm{~N}_{4}$, and then it was heated in a Teflon-lined autoclave at $373 \mathrm{~K}$ for 24 hours. After the treatment, the precipitates were centrifuged and washed with deionized water several times to remove $\mathrm{Na}^{+}$ion and then dried in a vacuum drying oven at $333 \mathrm{~K}$ overnight. This sample is denoted as HT-g- $\mathrm{C}_{3} \mathrm{~N}_{4}$.

\subsection{Preparation of a composite photocatalyst by a planetary mill}

The composite sample of $\mathrm{WO}_{3}$ and original $\mathrm{g}-\mathrm{C}_{3} \mathrm{~N}_{4}$ was prepared as follows. One gram of $\mathrm{WO}_{3}$ and original $\mathrm{g}-\mathrm{C}_{3} \mathrm{~N}_{4}$ powder and $20 \mathrm{~mL}$ of deionized water were added to a $50 \mathrm{~mL}$ agate bowl containing $50 \mathrm{~g}$ of yttrium-stabilized zirconia grinding beads (Nikkato Co., $=0.6 \mathrm{~mm}$ ). Then the agate bowl was put on a planetary mill (Fritsch Japan Co., Planetary Micro Mill pulverisette 7) and the planetary mill was operated at $750 \mathrm{rpm}$ for $10 \mathrm{~min}$. After removing the beads by screening, the sample was separated by filtration, washed with deionized water several times, and dried in a vacuum drying oven at $333 \mathrm{~K}$ overnight. This composite sample is denoted as $\mathrm{CNWx}$, where $\mathrm{x}$ is the weight percent of $\mathrm{WO}_{3}$ included in the composite sample. The composite sample of $\mathrm{WO}_{3}$ and $\mathrm{HT}-\mathrm{g}-\mathrm{C}_{3} \mathrm{~N}_{4}$ was prepared by the same procedure as that for CNWx. This composite sample is denoted as HTWx. As a reference, each sample, i.e., original g- $\mathrm{C}_{3} \mathrm{~N}_{4}, \mathrm{HT}-\mathrm{g}-\mathrm{C}_{3} \mathrm{~N}_{4}$ and $\mathrm{WO}_{3}$, was treated by the same procedure. These composite samples are denoted as CNW0, HTW0 and $\mathrm{PM}-\mathrm{WO}_{3}$, respectively.

\subsection{Characterization}

Crystal structures of the obtained samples were characterized by an X-ray diffractometer (Rigaku, MiniFlex II) equipped with a $\mathrm{Cu} \mathrm{K} \alpha$ irradiation source. The morphology of prepared particles was observed by field emission scanning electron microscopy (FE-SEM; JEOL, JSM-6701FONO). Diffuse reflectance spectra (DRS) were measured using a UV-vis spectrophotometer (Shimadzu, UV-2600) equipped with an integrating sphere unit (Shimadzu, ISR-2600 Plus). Specific surface area (SBET) was determined with a surface area analyzer (Quantachrome, Nova 4200e) by the Brunauer-Emmett-Teller method. Functional group vibrations were confirmed by using a Fourier transform infrared spectrometer (FTIR; JASCO, FT / IR 
4200) with a diffuse reflectance accessory (JASCO, DR-81). Fluorescence spectra were obtained using a photoluminescence spectrometer (JASCO, FP-8500).

\subsection{Photocatalytic measurement}

Before evaluation of the photocatalytic activity, each sample was irradiated with UV light using black light (UVP, XX-15BLB) in order to remove organic contaminants on the sample. The photocatalytic activity of the composite sample was evaluated by $\mathrm{CO}_{2}$ liberation from photocatalytic mineralization of acetaldehyde. One hundred milligrams of powder, which has complete extinction of incident radiation, was spread on the bottom of a glass dish, and the glass dish was placed in a Tedlar bag (AS ONE Co. Ltd.). Then $125 \mathrm{~cm}^{3}$ artificial air containing $1000 \mathrm{ppm}$ of acetaldehyde was injected into the bag. Photoirradiation was performed at room temperature after the acetaldehyde had reached adsorption equilibrium. A light-emitting diode (LED; Epitex, L435-30M32L), which emitted light at wavelengths of ca. $435 \mathrm{~nm}$, was used as a light

source, and its intensity was controlled by $1.0 \mathrm{~mW} \mathrm{~cm}^{-2}$. The concentration of $\mathrm{CO}_{2}$ was observed by gas chromatography (Shimadzu GC-8A, FID detector) equipped with a Porapak N packed column and a methanizer (GL Science, MT-221) as a function of irradiation time.

\section{Results and discussion}

\subsection{Characterization of $\mathrm{g}-\mathrm{C}_{3} \mathrm{~N}_{4}$ and $\mathrm{HT}-\mathrm{g}-\mathrm{C}_{3} \mathrm{~N}_{4}$}

Figure 1A shows X-ray diffraction (XRD) patterns of original $g-\mathrm{C}_{3} \mathrm{~N}_{4}$ and HT-g- $\mathrm{C}_{3} \mathrm{~N}_{4}$ samples. The original g- $\mathrm{C}_{3} \mathrm{~N}_{4}$ had two peaks at $13.1^{\circ}$ and $27.6^{\circ}$, which can be indexed as (100) and (002) diffraction planes (JCPDS 87-1526). Similarly, the XRD pattern of HT-g- $\mathrm{C}_{3} \mathrm{~N}_{4}$ also had characteristic peaks at $27.6^{\circ}$, suggesting that HT-g- $\mathrm{C}_{3} \mathrm{~N}_{4}$ has the same crystal structure as that of original $g-\mathrm{C}_{3} \mathrm{~N}_{4}$ (Fig. 1C). The low-angle reflection peak at $13.1^{\circ}$ becomes less pronounced due to decreased planar size of the layers during $\mathrm{NaOH}$ solution etching of original g- $\mathrm{C}_{3} \mathrm{~N}_{4}[26,27]$. Functional groups of original g- $\mathrm{C}_{3} \mathrm{~N}_{4}$ and $\mathrm{HT}-\mathrm{g}-\mathrm{C}_{3} \mathrm{~N}_{4}$ were confirmed by FT-IR spectroscopy. As shown in Fig. 1B, the characteristic IR spectrum of $\mathrm{HT}-\mathrm{g}-\mathrm{C}_{3} \mathrm{~N}_{4}$ was similar to that of original $\mathrm{g}-\mathrm{C}_{3} \mathrm{~N}_{4}$ : a peak at about $810 \mathrm{~cm}^{-1}$ originating from the heptazine ring system and peaks in the region from 900 to $1800 \mathrm{~cm}^{-1}$ attributed to either trigonal C-N(-C)-C or bridging C-NH-C units 
were observed in both samples. UV-vis DRS are shown in Fig. 1C. Compared with the spectrum of original g- $\mathrm{C}_{3} \mathrm{~N}_{4}$, the spectrum of HT-g- $\mathrm{C}_{3} \mathrm{~N}_{4}$ was shifted to longer wavelengths. A similar blue shift of peak wavelength was observed in fluorescence emission spectra (Fig. 1D). These results are presumably due to decrease in particle size $[27,28]$. Actually, the $\mathrm{SBET}_{\mathrm{BET}}$ of $\mathrm{g}-\mathrm{C}_{3} \mathrm{~N}_{4}$ was enlarged from $11 \mathrm{~m}^{2} \mathrm{~g}^{-1}$ to $50 \mathrm{~m}^{2} \mathrm{~g}^{-1}$ by hydrothermal treatment. Fig. 2 shows SEM images of original $g-\mathrm{C}_{3} \mathrm{~N}_{4}$ and HT-g- $\mathrm{C}_{3} \mathrm{~N}_{4}$ samples. The original g- $\mathrm{C}_{3} \mathrm{~N}_{4}$ was plate-like particles (Fig. 2A), while HT-g- $\mathrm{C}_{3} \mathrm{~N}_{4}$ had an uneven surface (Fig. 2B). This indicates that the surface of $\mathrm{g}-\mathrm{C}_{3} \mathrm{~N}_{4}$ particles was etched by hydrothermal treatment in $\mathrm{NaOH}$ solution, resulting in enlargement of SBET without any change in crystal structure. These results coincide with the results of reported study [26].

Photocatalytic activity of original $\mathrm{g}-\mathrm{C}_{3} \mathrm{~N}_{4}$ and $\mathrm{HT}-\mathrm{g}-\mathrm{C}_{3} \mathrm{~N}_{4}$ was evaluated by $\mathrm{CO}_{2}$ liberation from decomposition of acetaldehyde. Figure 3 shows the time courses of $\mathrm{CO}_{2}$ liberation over original g- $\mathrm{C}_{3} \mathrm{~N}_{4}$ and HT-g- $\mathrm{C}_{3} \mathrm{~N}_{4}$. Although HT-g- $\mathrm{C}_{3} \mathrm{~N}_{4}$ showed smaller visible-light absorption than that of original g- $\mathrm{C}_{3} \mathrm{~N}_{4}$, it showed 3-times greater $\mathrm{CO}_{2}$ liberation due to large $\mathrm{S}_{\mathrm{BET}}$, which increase in adsorption, reduction and oxidation sites. However, $\mathrm{CO}_{2}$ liberation for 48 hours was much smaller than $2000 \mathrm{ppm}$, which means complete decomposition of acetaldehyde into $\mathrm{CO}_{2}$, due its low oxidation ability [19].

\subsection{Characterization of CNWx and HTWx}

Powder XRD patterns of CNWx samples are shown in Fig. 4A. XRD patterns showed only peaks attributed to $\mathrm{g}-\mathrm{C}_{3} \mathrm{~N}_{4}$ and $\mathrm{WO}_{3}$, and peaks attributed to other components were not detected. Although a peak at $27.6^{\circ}$, which was attributed to $(002)$ of $\mathrm{g}-\mathrm{C}_{3} \mathrm{~N}_{4}$, was observed in $\mathrm{XRD}$ patterns of $\mathrm{CNWx}(\mathrm{x}<50)$ samples, XRD patterns of CNWx $(x>50)$ samples showed no appreciable peak around $27.6^{\circ}$ due to weak diffraction intensity of $\mathrm{g}-\mathrm{C}_{3} \mathrm{~N}_{4}$. On the other hand, peaks attributed to $\mathrm{WO}_{3}$ could be observed in all CNWx samples ( $\mathrm{x}$ $>0$ ), and no changes in peak pattern and width of the peak at $24.3^{\circ}$ were observed, compared with original $\mathrm{WO}_{3}$ (Fig. 4, S1). This is reasonable since $\mathrm{PM}-\mathrm{WO}_{3}$ showed the same pattern and width of peak at $24.3^{\circ}$ as original $\mathrm{WO}_{3}$. In contrast, $\mathrm{CNW} 0$ showed a larger peak width at $27.6^{\circ}$ than that of original $\mathrm{g}-\mathrm{C}_{3} \mathrm{~N}_{4}$. This result coincides with enlargement of $\mathrm{S}_{\mathrm{BET}}$ by planetary mill treatment (Fig. 5). A similar result was obtained for HTWx samples (Fig. 4B).

Figure 6 shows SEM images of $\mathrm{PM}-\mathrm{WO}_{3}, \mathrm{CNWx}$ and HTWx. PM-WO 3 showed aggregated particles with 
particle size of a few hundreds of nanometers (Fig. 5), and the morphology and $\mathrm{S}_{\mathrm{BET}}$ of $\mathrm{WO}_{3}$ particles were slightly changed by planetary mill treatment (Fig. 5). On the other hand, plate-like particles were pulverized into small particles by the planetary mill treatment in SEM images of CNW0 and HTW0 samples (Fig. S2). This agreed with increase in $\mathrm{S}_{\mathrm{BET}}$ (Fig. 5). For CNWx $(\mathrm{x}>0)$ samples, it seemed that $\mathrm{WO}_{3}$ particles attached to the surface of $\mathrm{g}-\mathrm{C}_{3} \mathrm{~N}_{4}$ increased with an increase in $\mathrm{WO}_{3}$ content. When the $\mathrm{WO}_{3}$ content was above 80 $\mathrm{wt} \%$, the $\mathrm{g}-\mathrm{C}_{3} \mathrm{~N}_{4}$ particles were almost completely covered by $\mathrm{WO}_{3}$ particles. The same result was also found in HTWx $(\mathrm{x}>0)$ samples.

Figure 7 shows UV-vis DRS of PM-WO3, CNWx and HTWx. DRS of CNW0 and HTW0 were blue-shifted compared with those of original g- $\mathrm{C}_{3} \mathrm{~N}_{4}$ and HT-g- $\mathrm{C}_{3} \mathrm{~N}_{4}$ (Fig. S3). This blue shift is presumably due to decrease in particle size by planetary mill treatment $[27,28]$, as observed in SBET. Photoabsorption at the wavelength of $435 \mathrm{~nm}$ of HTWx samples increased with increase in $\mathrm{WO}_{3}$ content, and it was smaller

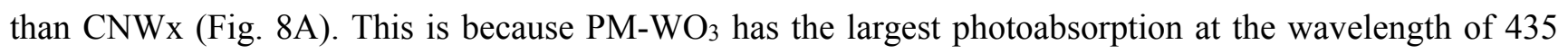
$\mathrm{nm}$, followed in order by CNW0 and HTW0. On the other hand, photoabsorption at a longer wavelength of $500 \mathrm{~nm}$, which was observed in the DRS of $\mathrm{WO}_{3}$, was suppressed by composition with a small amount of g- $\mathrm{C}_{3} \mathrm{~N}_{4}$. Figure $8 \mathrm{~B}$ shows relative reflectance of $\mathrm{CNWx}$ and HTWx samples at the wavelength of $800 \mathrm{~nm}$ as a function of $\mathrm{WO}_{3}$ content. CNWx and HTWx samples showed no linear relationship between relative reflectance at the wavelength of $800 \mathrm{~nm}$ and $\mathrm{WO}_{3}$ content. Since photoabsorption at a longer wavelength of $500 \mathrm{~nm}$ is attributed to the $\mathrm{W}^{5+}$ state in $\mathrm{WO}_{3}$, which is generated by electron accumulation in $\mathrm{WO}_{3}$ and reduction treatment of $\mathrm{WO}_{3}$ [29-31], a nonlinear relationship means that electron accumulation in $\mathrm{WO}_{3}$ was decreased by composition with $\mathrm{g}-\mathrm{C}_{3} \mathrm{~N}_{4}$. A similar phenomenon was observed in the Z-scheme composite photocatalyst of $\mathrm{WO}_{3}$ and $\mathrm{CaFe}_{2} \mathrm{O}_{4}[13]$.

\subsection{Photocatalytic activity for acetaldehyde decomposition}

The photocatalytic activities of the prepared samples were evaluated by $\mathrm{CO}_{2}$ liberation from photocatalytic mineralization of acetaldehyde. Figure 9A shows the time courses of $\mathrm{CO}_{2}$ liberation of the CNWx samples and $\mathrm{PM}-\mathrm{WO}_{3} \cdot \mathrm{WO}_{3}$ showed a high $\mathrm{CO}_{2}$ liberation rate at the beginning of photoirradiation, but $\mathrm{CO}_{2}$ liberation stopped with longer photoirradiation before reaching $2000 \mathrm{ppm}$, which means complete decomposition of $1000 \mathrm{ppm}$ acetaldehyde. $\mathrm{WO}_{3}$ can partially decompose acetaldehyde to formaldehyde or 
formic acid with $\mathrm{CO}_{2}$ liberation [15], but it cannot completely decompose these molecules to $\mathrm{CO}_{2}$ without efficient electron consumption [16]. In contrast, almost all of the composite samples showed no saturation tendency of $\mathrm{CO}_{2}$ liberation with irradiation time and a larger amount of $\mathrm{CO}_{2}$ liberation for 48 hours. This implies that electron consumption in $\mathrm{WO}_{3}$ was promoted by composition with $\mathrm{g}-\mathrm{C}_{3} \mathrm{~N}_{4}$, as observed in $\mathrm{WO}_{3}$ composed with other semiconductors or metals $[15-17,20,21]$. Actually, results from UV-vis DRS of CNWx and HTWx samples indicate that electron accumulation in $\mathrm{WO}_{3}$ is suppressed by composition of g- $\mathrm{C}_{3} \mathrm{~N}_{4}$ (Fig. 8B). Since g- $\mathrm{C}_{3} \mathrm{~N}_{4}$ is a semiconductor with more negative $\mathrm{CB}$ potential than that of $\mathrm{WO}_{3}$ and one-electron reduction potential of $\mathrm{O}_{2}$, a plausible mechanism is $\mathrm{Z}$-scheme reaction accompanied by electron transfer from the $\mathrm{CB}$ of $\mathrm{WO}_{3}$ to the $\mathrm{VB}$ of $\mathrm{g}-\mathrm{C}_{3} \mathrm{~N}_{4}$ (Fig. 10). Thus, all $\mathrm{WO}_{3}$ particles are required to be attached on all g- $\mathrm{C}_{3} \mathrm{~N}_{4}$ particles for efficient charge transfer. Otherwise, acetaldehyde on non-composite g- $\mathrm{C}_{3} \mathrm{~N}_{4}$ and $\mathrm{WO}_{3}$ remained without being decomposed completely into $\mathrm{CO}_{2}$. This is the reason why $\mathrm{CNWx}$ with a large amount of $\mathrm{WO}_{3}$ showed a saturation tendency and $\mathrm{CNWx}$ with a small amount of $\mathrm{WO}_{3}$ showed a low rate of $\mathrm{CO}_{2}$ liberation.

Figure 9B shows the time courses of $\mathrm{CO}_{2}$ liberation of the HTWx composites and PM-WO3. HTWx samples also showed similar enhancement for $\mathrm{CO}_{2}$ liberation by the composition as observed in $\mathrm{CNWx}$ samples. However, HTWx $(\mathrm{x}>0)$ samples showed slightly larger $\mathrm{CO}_{2}$ liberation than that of $\mathrm{CNWx}(\mathrm{x}>0)$, though $\mathrm{CO}_{2}$ liberation of HTW0 was twice larger than that of CNW0 for 48 hours. This can be explained as follows. $\mathrm{g}-\mathrm{C}_{3} \mathrm{~N}_{4}$ in composite samples predominantly works as not an adsorption and oxidation site for organic compounds but a reduction site for $\mathrm{O}_{2}$, while adsorption, oxidation and reduction must all proceed on single $\mathrm{g}-\mathrm{C}_{3} \mathrm{~N}_{4}$. Therefore, enhancement of $\mathrm{S}_{\mathrm{BET}}$ of $\mathrm{g}-\mathrm{C}_{3} \mathrm{~N}_{4}$ in a composite sample is thought to show no direct contribution to oxidation of acetaldehyde because acetaldehyde is hardly decomposed over g- $\mathrm{C}_{3} \mathrm{~N}_{4}$ in the composite photocatalyst.

Figure 9C shows $\mathrm{CO}_{2}$ liberation for 48 hours of CNWx and HTWx samples as a function of $\mathrm{WO}_{3}$ content. A volcano-like relationship was observed in both CNWx and HTWx samples, but HTWx samples with a larger amount of $\mathrm{WO}_{3}$ showed larger $\mathrm{CO}_{2}$ liberation because larger $\mathrm{S}_{\mathrm{BET}}$ of $\mathrm{g}_{-} \mathrm{C}_{3} \mathrm{~N}_{4}$ in $\mathrm{HTWx}$ samples increased contact points between $\mathrm{g}-\mathrm{C}_{3} \mathrm{~N}_{4}$ and $\mathrm{WO}_{3}$. However, optimized $\mathrm{HTWx}$ showed slightly larger $\mathrm{CO}_{2}$ liberation than that of CNWx, and the optimum ratio of $\mathrm{WO}_{3}$ in HTWx samples was the same as that in CNWx samples despite larger SBEt. This is due to smaller photoabsorption of HTW0 than that of CNW0, as 
seen in Fig. 8A.

Figure 9D shows UV-vis DRS of PM-WO3, CNW50 and HTW50 before and after photocatalytic reaction. After photocatalytic reaction, photoabsorption of $\mathrm{PM}-\mathrm{WO}_{3}$ at wavelengths from $500 \mathrm{~nm}$ to $800 \mathrm{~nm}$ showed greatly increased, which is attributed to the partial reduction of $\mathrm{W}^{6+}$ to $\mathrm{W}^{5+}$ by photoexcited electrons. In the case of CNW50 and HTW50, no obvious changes can be found from DRS of the composite photocatalysts before and after photocatalytic reaction. The results indicate that the self-reduction process by photogenerated electrons in $\mathrm{WO}_{3}$ are prevented after composite with $\mathrm{g}_{-} \mathrm{C}_{3} \mathrm{~N}_{4}$ or $\mathrm{HT}-\mathrm{g}-\mathrm{C}_{3} \mathrm{~N}_{4}$, because photogenerated electrons in $\mathrm{CB}$ of $\mathrm{WO}_{3}$ should be efficiently consumed by the reaction with photogenerated holes in VB of $\mathrm{g}-\mathrm{C}_{3} \mathrm{~N}_{4}$ or HT-g- $\mathrm{C}_{3} \mathrm{~N}_{4}$. This means that the composite photocatalysts follow Z-scheme charge separation mechanism.

Larger $\mathrm{CO}_{2}$ liberation over composite samples may be attributed to decomposition of $\mathrm{g}-\mathrm{C}_{3} \mathrm{~N}_{4}$. Therefore, we confirmed stability of $\mathrm{g}-\mathrm{C}_{3} \mathrm{~N}_{4}$ in the prepared samples by a self-decomposition test. Figure $\mathrm{S} 4$ shows the time courses of $\mathrm{CO}_{2}$ liberation over CNW50 and HTW50 in the presence and absence of acetaldehyde. Although slight $\mathrm{CO}_{2}$ liberation was observed in CNW50 and HTW50 samples, it was much smaller than $\mathrm{CO}_{2}$ liberation in the presence of acetaldehyde. This confirmed that enlargement of $\mathrm{CO}_{2}$ was not due to decomposition of $\mathrm{g}_{-} \mathrm{C}_{3} \mathrm{~N}_{4}$. In the HTW50 sample, $1600 \mathrm{ppm}$ of $\mathrm{CO}_{2}$ was observed after 48 hours of photoirradiation, indicating that at least $600 \mathrm{ppm}$ of acetaldehyde had been completely decomposed into $1200 \mathrm{ppm}$ of $\mathrm{CO}_{2}$. This "partial complete oxidation" is also collateral evidence for Z-scheme charge transfer in the composite photocatalyst because complete oxidation of acetaldehyde into $\mathrm{CO}_{2}$ cannot occur over $\mathrm{WO}_{3}$ without a metal co-catalyst or semiconductor for Z-scheme charge transfer.

\section{Conclusions}

In this study, a highly active photocatalyst under visible-light irradiation for organic decomposition was synthesized by a composite of $\mathrm{g}-\mathrm{C}_{3} \mathrm{~N}_{4}$ and $\mathrm{WO}_{3}$ using a planetary mill. UV-vis DRS and photocatalytic evaluation indicated that the composite photocatalysts show high activity as a result of Z-scheme reaction. The optimized composite samples prepared in the present study showed complete oxidation of "most of all" acetaldehyde into $\mathrm{CO}_{2}$ by Z-scheme reaction, unlike previously reported composite photocatalysts [22-24]. For further enhancement of photocatalytic activity under visible-light irradiation, a composite photocatalyst 
with both large visible-light absorption and a large number of contact points between $\mathrm{g}-\mathrm{C}_{3} \mathrm{~N}_{4}$ and $\mathrm{WO}_{3}$ is needed. 
Acknowledgments

This work was supported by the JST PRESTO program and the JST ACT-C program. 
[1] K. Hashimoto, H. Irie, A. Fujishima, Japanese Journal of Applied Physics 44 (2005) 8269-8285.

[2] T. Ohno, M. Akiyoshi, T. Umebayashi, K. Asai, T. Mitsui, M. Matsumura, Applied Catalysis A: General 265 (2004) 115-121.

[3] T. Ohno, T. Tsubota, K. Nishijima, Z. Miyamoto, Chemistry Letters 33 (2004) 750-751.

[4] S. Sato, J. M. White, Journal of the American Chemical Society 102 (1980) 7206-7210.

[5] N. Murakami, Y. Kurihara, T. Tsubota, T. Ohno, The Journal of Physical Chemistry C 113 (2009) 3062-3069.

[6] T. Ohno, K. Sarukawa, M. Matsumura, New Journal of Chemistry 26 (2002) 1167-1170.

[7] S.C. Yan, S.B. Lv, Z.S. Li, Z.G. Zou, Dalton Transactions 39 (2010) 1488-1491.

[8] A.K. Chakraborty, M.A. Kebede, Reaction Kinetics, Mechanisms and Catalysis 106 (2012) 83-98.

[9] Q. Xiang, J. Yu, M. Jaroniec, The Journal of Physical Chemistry C 115 (2011) 7355-7363.

[10] G.Z. Liao, S. Chen, X. Quan, H.T. Yu, H.M. Zhao, Journal of Materials Chemistry 22 (2012) 2721-2726.

[11] C. Pan, J. Xu , Y. Wang, D. Li, Y. Zhu, Advanced Functional Materials 22 (2012) 1518-1524.

[12] N. Serpone, P. Maruthamuthu, P. Pichat, E. Pelizzetti, H. Hidaka, Journal of Photochemistry and Photobiology A: Chemistry 85 (1995) 247-255.

[13] Z.F. Liu, Z.G. Zhao, M. Miyauchi, Journal of Physical Chemistry C 113 (2009) 17132-17137.

[14] R. Abe, Bulletin of the Chemical Society of Japan 84 (2011) 1000-1030.

[15] T. Arai, M. Horiguchi, M. Yanagida, T. Gunji, H. Sugihara, K. Sayama, Journal of Physical Chemistry C 113 (2009) 6602-6609.

[16] T. Arai, M. Yanagida, Y. Konishi, Y. Iwasaki, H. Sugihara, K. Sayama, Catalysis Communications 9 (2008) 1254-1258.

[17] T. Arai, M. Yanagida, Y. Konishi, Y. Iwasaki, H. Sugihara, K. Sayama, Journal of Physical Chemistry C 111 (2007) 7574-7577.

[18] X.C. Wang, K. Maeda, A. Thomas, K. Takanabe, G. Xin, J.M. Carlsson, K. Domen, M. Antonietti, Nature Materials 8 (2009) 76-80.

[19] K. Kondo, N. Murakami, C. Ye, T. Tsubota, T. Ohno, Applied Catalysis B: Environmental 142-143 (2013) 362- 367.

[20] R. Abe, H. Takami, N. Murakami, B. Ohtani, Journal of the American Chemical Society 130 (2008) $7780-7781$.

[21] T. Arai, M. Horiguchi, M. Yanagida, T. Gunji, H. Sugihara, K. Sayama, Chemical Communications (2008) 5565-5567.

[22] K. Katsumata, R. Motoyoshi, N. Matsushita, K. Okada, Journal of Hazardous Materials 260 (2013) 475-482.

[23] H. Yan, X. Zhang, S. Zhou, X. Xie, Y. Luo, Y. Yu, Journal of Alloys and Compounds 509 (2011) L232-L235.

[24] L. Huang, H. Xu, Y. Li, H. Li, X. Cheng, J. Xia, Y. Xua, Guobin Caia, Dalton Transactions 42 (2013) 8606-8616.

[25] S.C. Yan , Z.S. Li, Z.G. Zou, Langmuir 25 (2009) 10397-10401.

[26] T. Sano, S. Tsutsui, K. Koike, T. Hirakawa, Y. Teramoto, N. Negishi, K. Takeuchi, Journal of Materials 
Chemistry A 1 (2013) 6489-6496.

[27] M. Groenewolt, M. Antonietti, Advanced Materials 17 (2005) 1789-1792.

[28] P. Niu, L.L. Zhang, G. Liu, H.M. Cheng, Advanced Functional Materials 22 (2012) 4763-4770.

[29] M. Fujii, T. Kawai, H. Nakamatsu, S Kawai, Journal of the Chemical Society-Chemical Communications (1983) 1428-1429.

[30] Y. He, Z. Wu, L. Fu, C. Li, Y. Miao, L. Cao, H. Fan, B. Zou, Chemistry of Materials 15 (2003) 4039-4045.

[31] M. Miyauchi, M. Shibuya, Z. Zhao, Z. Liu, Journal of Physical Chemistry C 113 (2009) 10642-10646.

[32] J.S. Zhang, X.F. Chen, K. Takanabe, K. Maeda, K. Domen, J.D. Epping, X.Z. Fu, M. Antonietti, X.C. Wang, Angewandte Chemie-International Edition 49 (2010) 441-444.

[33] Y. Xu, M.A.A. Schoonen, American Mineralogist 85 (2000) 543-556. 
Figure Captions

Fig. 1 (A) XRD patterns, (B) FTIR spectra, (C) UV-vis DRS and (D) fluorescence emission spectra under excitation at the wavelength of $365 \mathrm{~nm}$ of original g- $\mathrm{C}_{3} \mathrm{~N}_{4}$ and $\mathrm{HT}-\mathrm{g}-\mathrm{C}_{3} \mathrm{~N}_{4}$.

Fig. 2 SEM images of (A) original $g-\mathrm{C}_{3} \mathrm{~N}_{4}$ and (B) HT-g- $\mathrm{C}_{3} \mathrm{~N}_{4}$.

Fig. 3 Time courses of $\mathrm{CO}_{2}$ liberation from acetaldehyde decomposition over original $\mathrm{g}-\mathrm{C}_{3} \mathrm{~N}_{4}$ and HT-g- $\mathrm{C}_{3} \mathrm{~N}_{4}$.

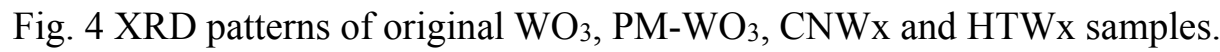

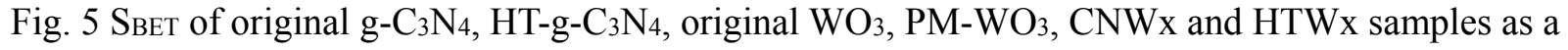
function of $\mathrm{WO}_{3}$ content.

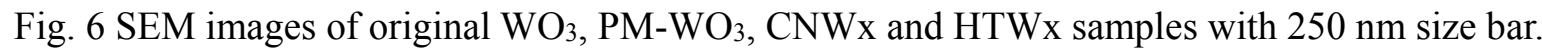

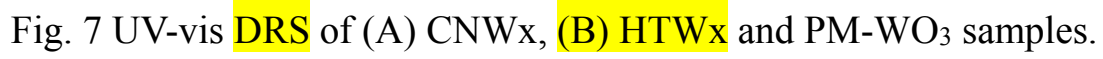

Fig. 8 Relative reflectance of CNWx and HTWx samples at the wavelengths of (A) $435 \mathrm{~nm}$ and (B) $800 \mathrm{~nm}$ as a function of $\mathrm{WO}_{3}$ content.

Fig. 9 Time courses of $\mathrm{CO}_{2}$ liberation from acetaldehyde decomposition over (A) CNWx and (B) HTWx samples. (C) $\mathrm{CO}_{2}$ liberation over $\mathrm{CNWx}$ and $\mathrm{HTWx}$ samples for 48 hours of photoirradiation as a function of $\mathrm{WO}_{3}$ content. (D) UV-vis DRS of PM-WO3, CNW50 and HTW50 before and after photocatalytic reaction.

Fig. 10 Schematic band structure of $g-\mathrm{C}_{3} \mathrm{~N}_{4}$ and $\mathrm{WO}_{3}$. The literature values for the band structure of $g-\mathrm{C}_{3} \mathrm{~N}_{4}$ [32] and $\mathrm{WO}_{3}[33]$ were used. 
Fig. 1
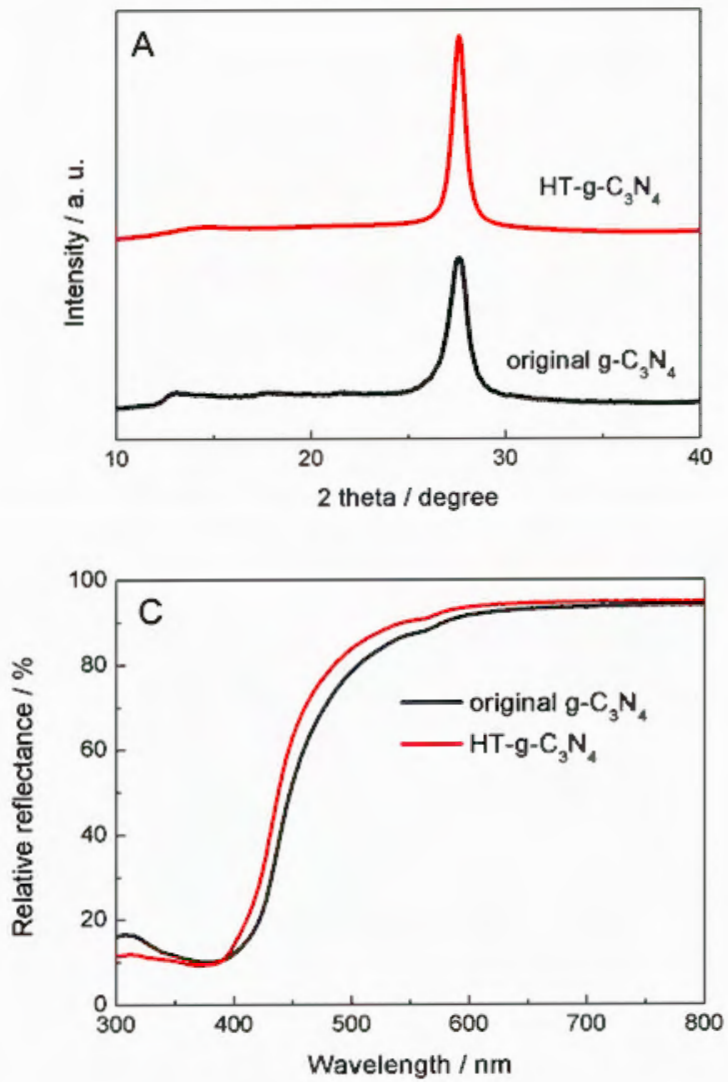
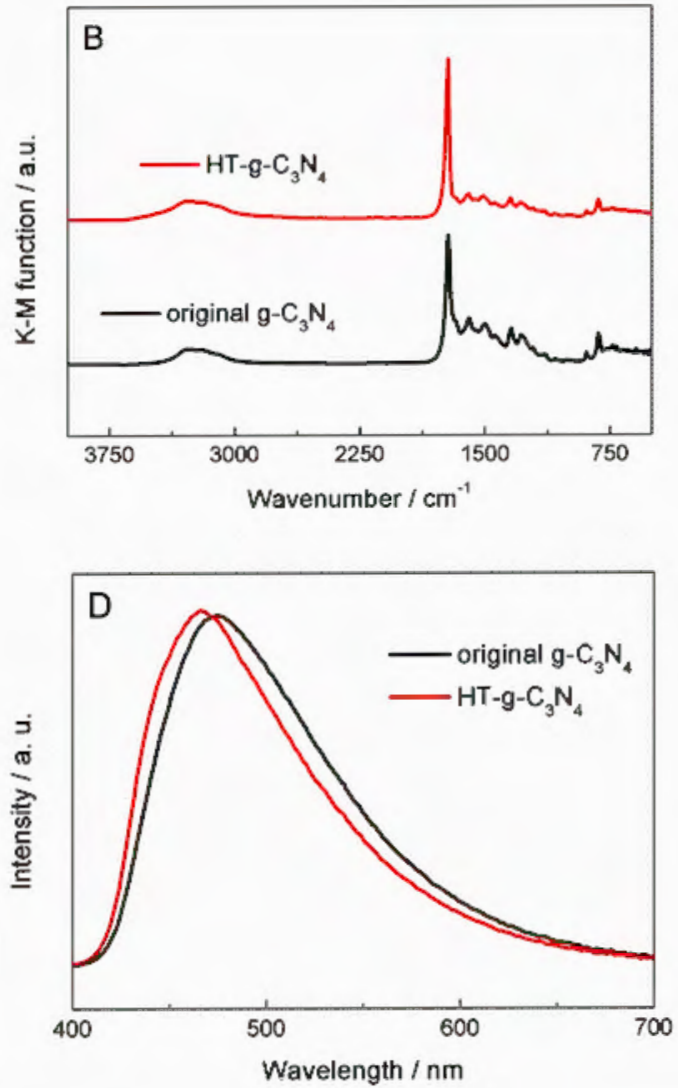
Fig. 2

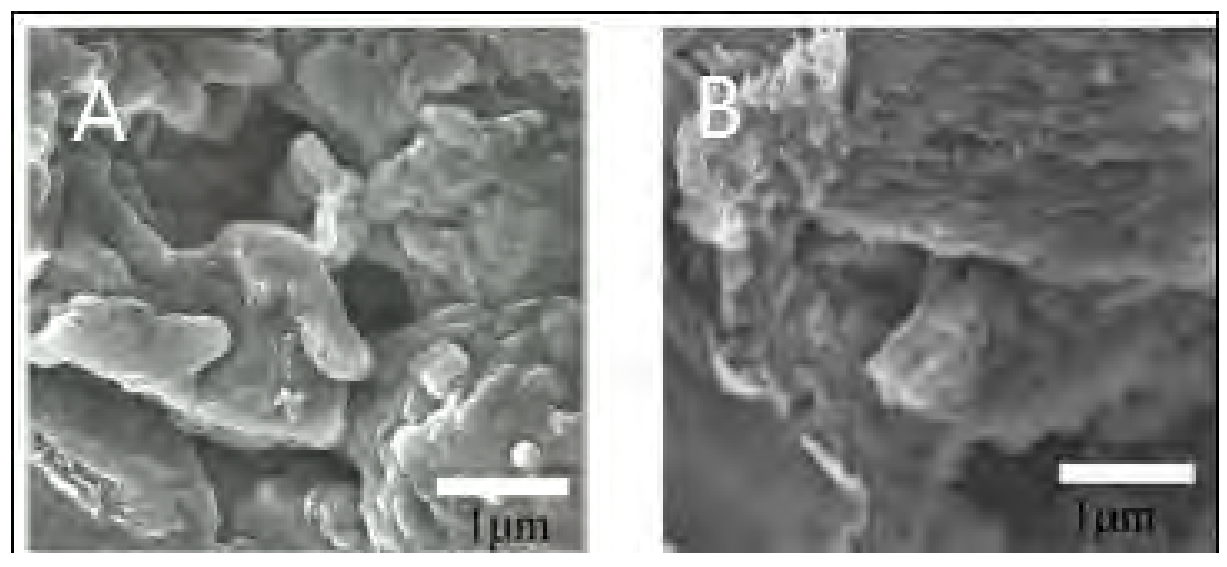


Fig. 3

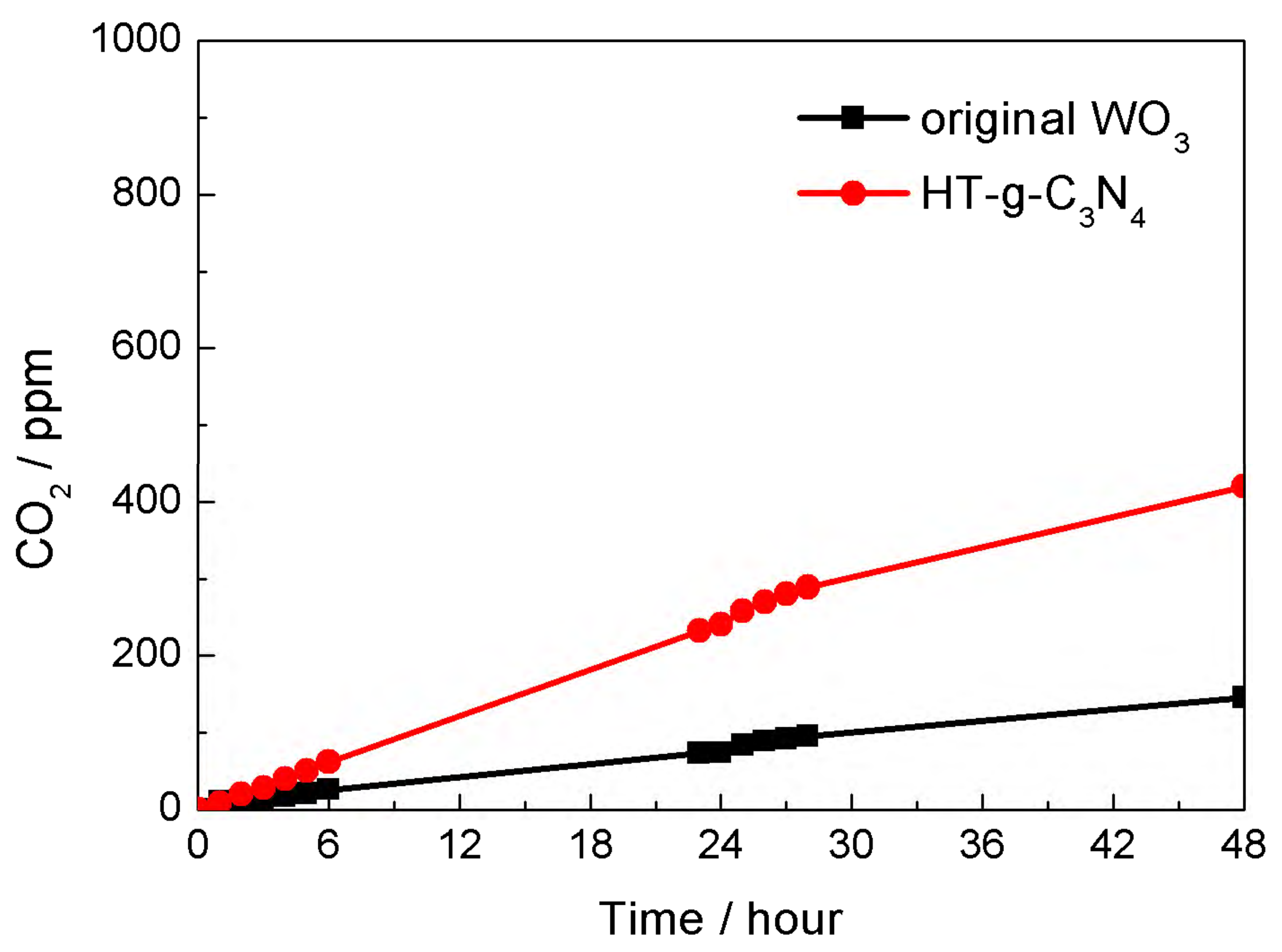


Fig. 4
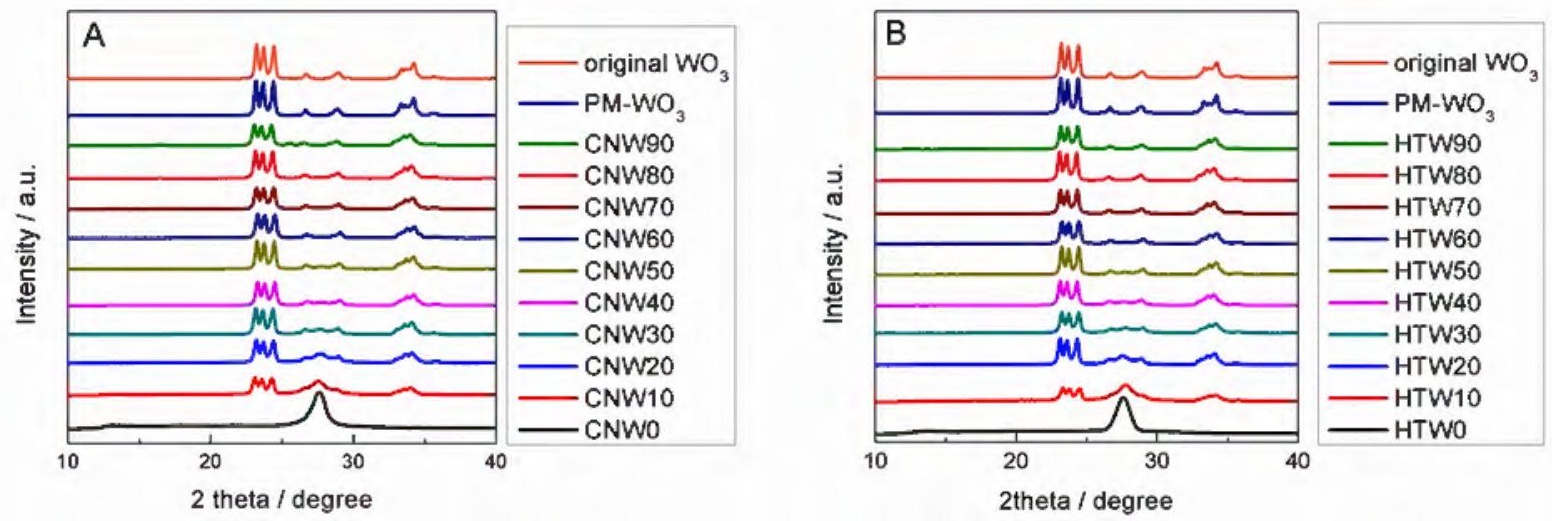
Fig. 5

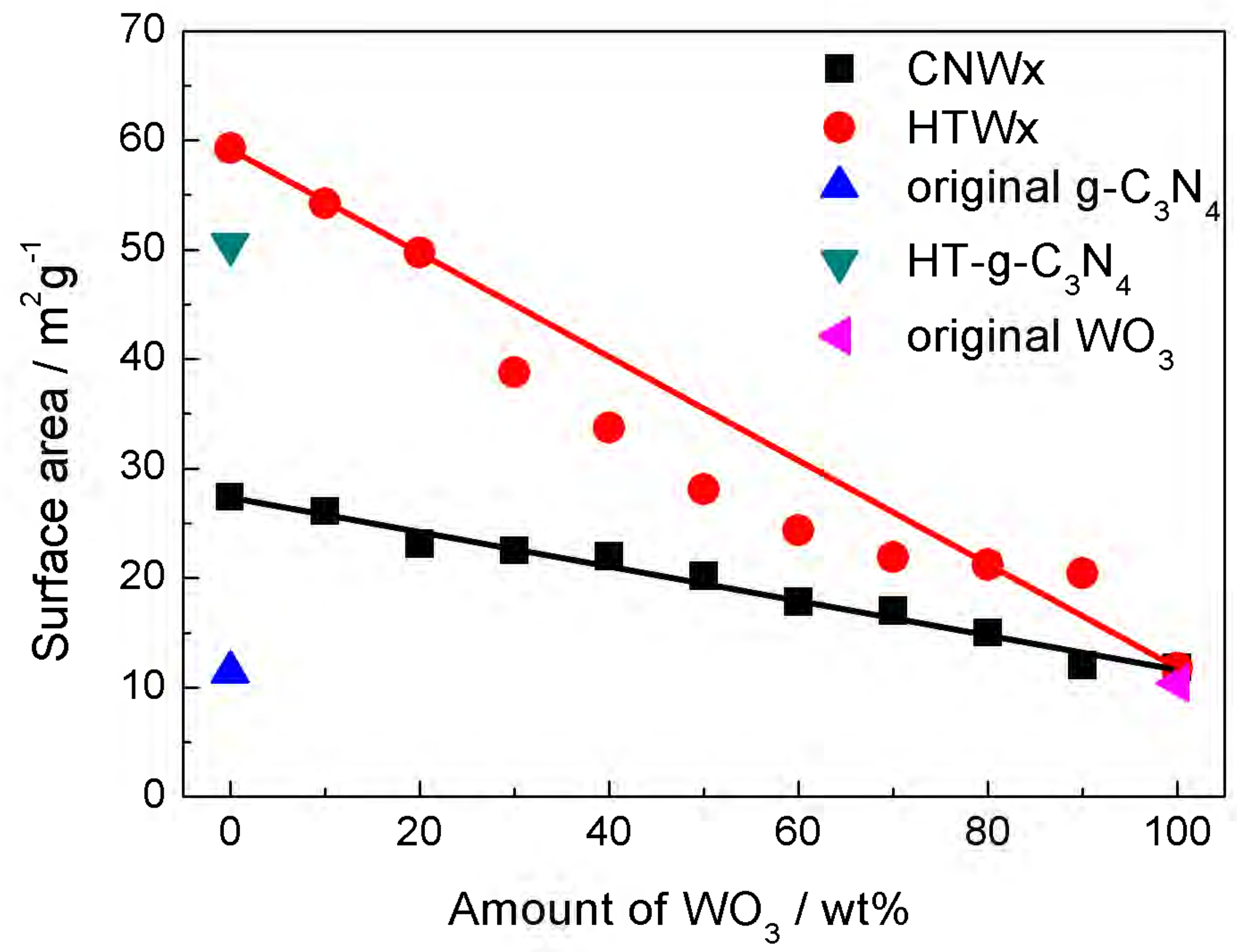


Fig. 6
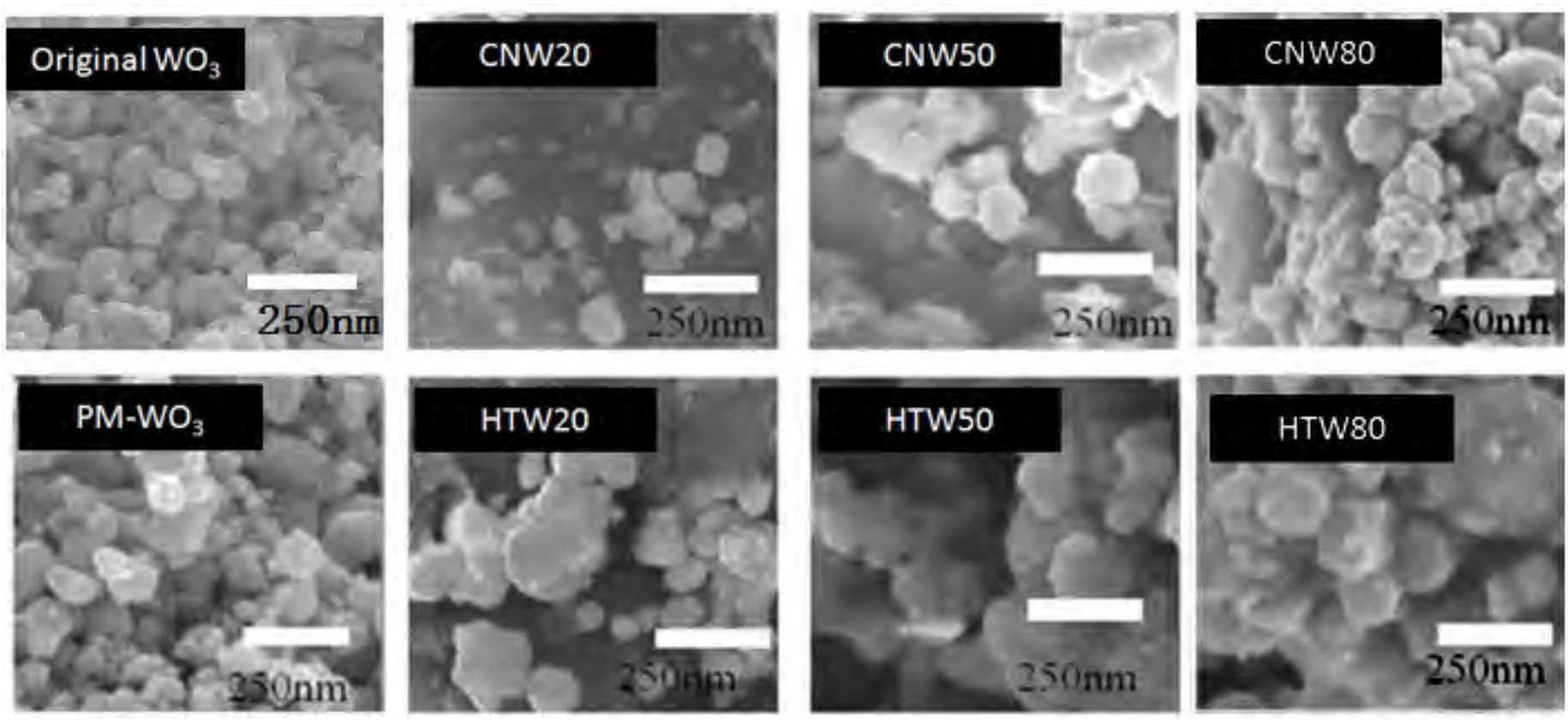
Fig. 7
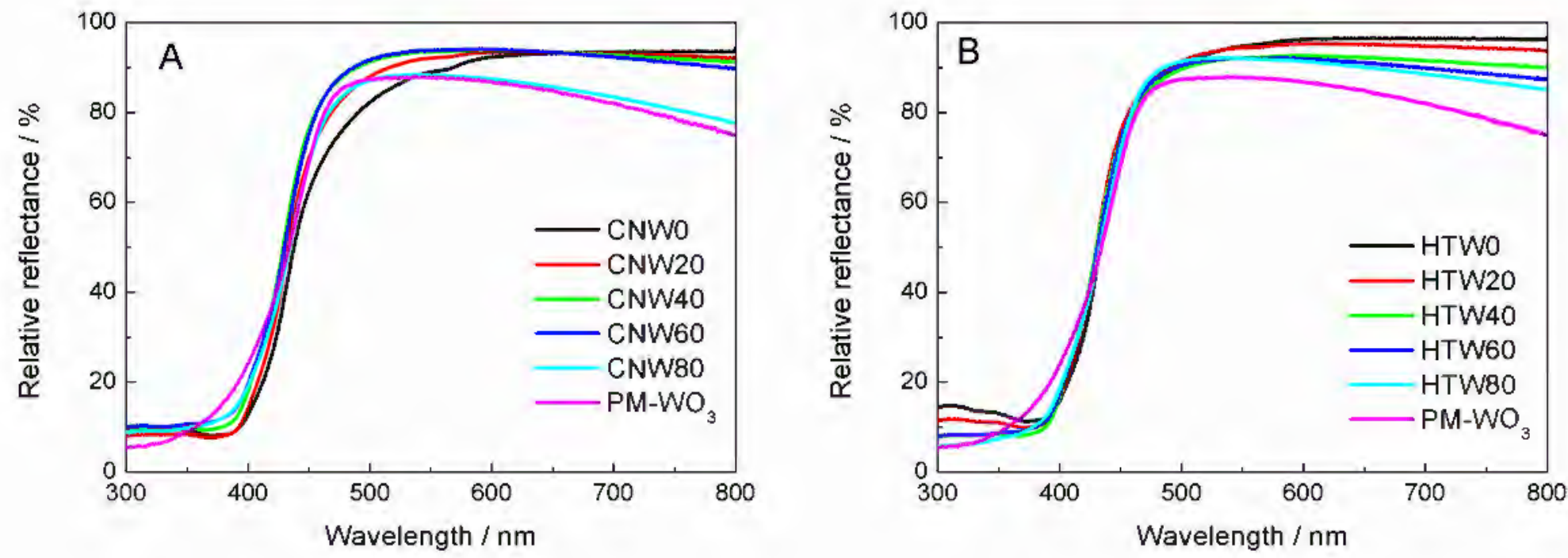

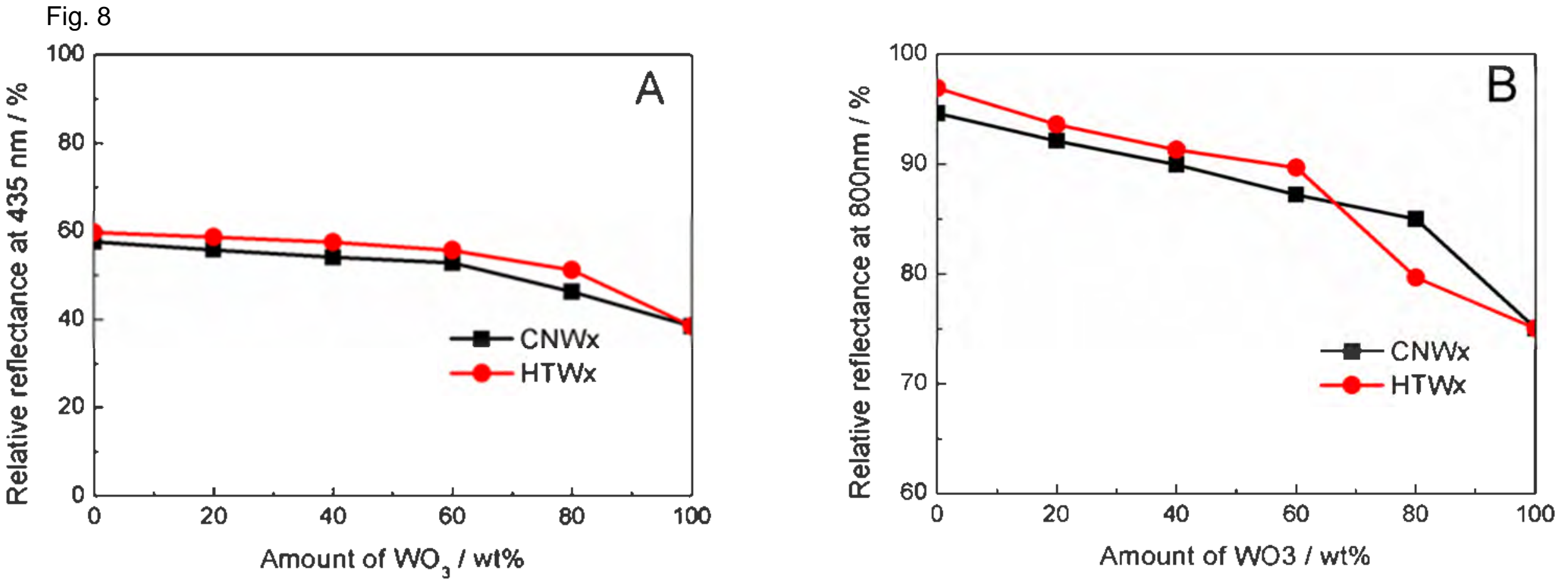
Fig. 9
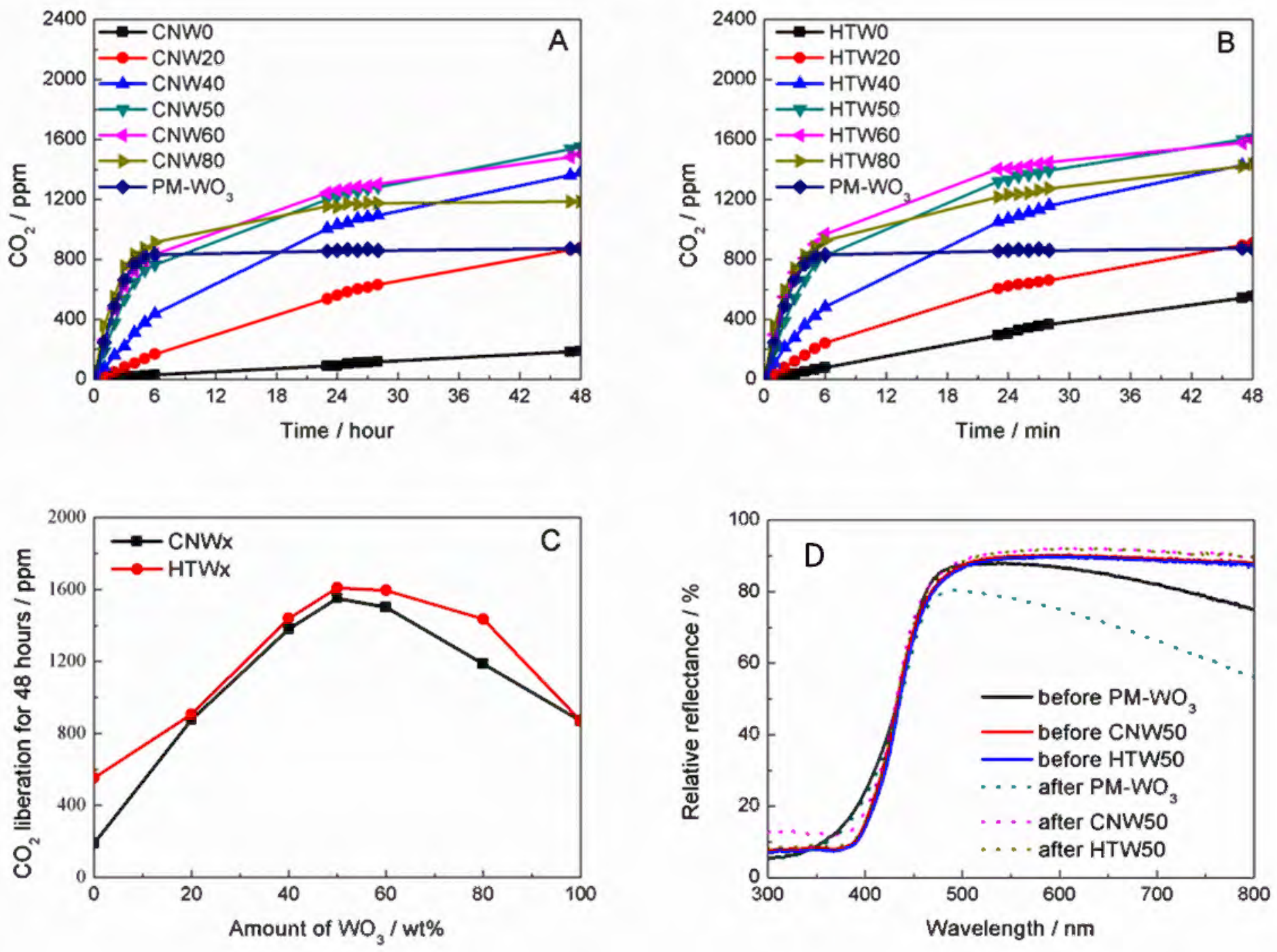
Fig. 10

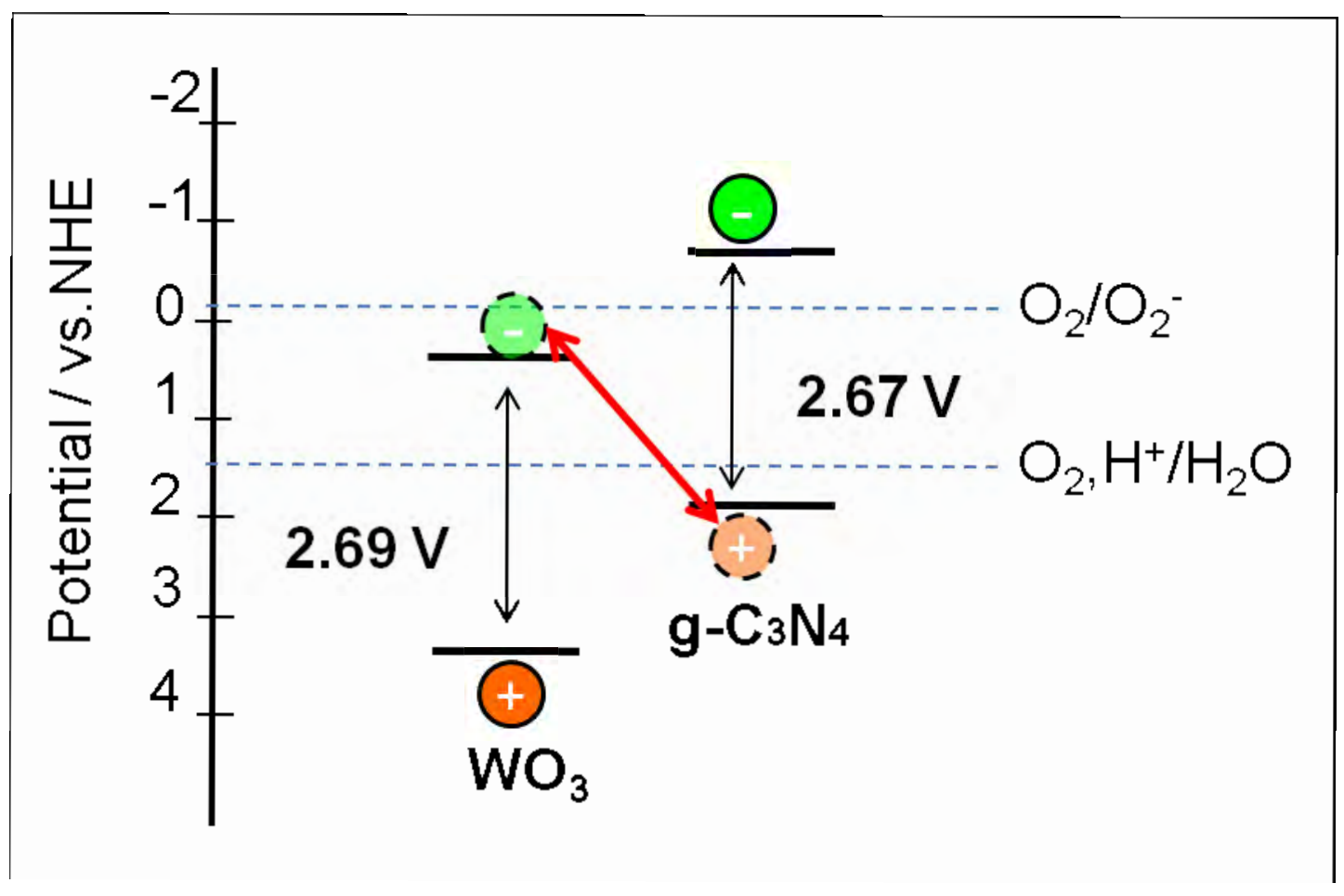

